\title{
FIELD PROBLEMS ON STREAM FISHES FOR SECONDARY CLASSES.
}

By T. L. Hankinson, State Normal School, Charleston, Illinois.

A field study of the fish life of a region is a branch of biology that can under some circumstances be carried on with profit by classes in secondary schools. Some essential conditions for such work with pupils of these schools are: a teacher interested in fish study and having sufficient training and knowledge to conduct the work; a stream or other body of water near the school, or easily reached by trolley or some handy mode of transportation, where collecting and observation work can be done; and a school schedule that will permit a few hours of field work by classes once or twice a week; and a laboratory at the school where indoor exercises can be carried on in connection with the field work such as studies of fish in aquaria, identification exercises, and examinations of contents of fish stomachs.

The kind of fish habitat most generally accessible to those who wish to do field work with secondary school classes is probably the small stream, and this paper will be limited almost entirely to a consideration of problems regarding fish of our creeks and brooks. An ideal small stream for study is a permanent one, that is, one which does not dry up in the summer, and has clear water and a variety of environmental conditions for fish, brought about by a winding course, variable depth, and differing character of bottom and shore.

Important observations can be made at any time of the year when the water is not too high or roily, and when not-frozen over with other than clear ice. A solid layer of transparent ice gives one an excellent opportunity to study stream fish in winter. The spring term is the best term for field studies with classes, for then nesting habits and migrations can be noted, and the subject is made especially attractive by the bright colors which the males of some species have only in spring, and then there is the interest lent by the pupils seeing the seasonal development of life in general during their consecutive visits to the stream.

As our field problems are chiefly ecological in nature, the fish habitats should be given attention, and before doing much else, it is necessary to get acquainted with our stream. One or more trips can be made for this purpose, and if possible, its 
whole course examined. It is desirable to make a map of the stream, or the part of it to be studied. This can be done by the class as a whole, or parts of the work may be assigned to different students. Perhaps some correlation between biology and mathematics can be brought in here, by the teacher of the lastnamed subject giving instructions in map making. Important features of the physiography of the stream valley, and the principal plant formations and numbers showing depths of water can all be shown on the map. When the final maps are produced, copies of them can be made by means of a hektograph or other duplicator so that each pupil can have one or more copies. These will be found almost indispensable in the stream studies for many important facts can be recorded on them, and they will facilitate note keeping. The work done in preparing the maps will make the pupils well accitainted with the stream. It is desirable to give some attention to the whole stream system to which ours belongs. Published maps, like the topographic maps of the Unitei States Geological Survey, when available, will be found very useful for this purpose. The water temperature ought to be laken and recorded at each visit, and the speed of the current noted. For comparative purposes the rough method of watching a small floating object go a certain distance and recording the time necessary for its journey can be used. In making the reconnaissance of the stream, it will be noted that all parts of it are not alike. Here is a deep hole; there is a riffle; in some places the bank is steep and bare of -vegetation; in other parts it is low and grassy, overhanging the water. We thus find different environmental conditions for fish in different parts of its course. It is a good plan to classify these habitats and select types of them for special study. For example, there may be many deep pools in the course of the stream, but only one or two typical ones can be given particular attention, and but a few of the matry areas of riffles need be studied intensively. Any one of these particular regions having similar environmental conditions for fish, selected for special study, is called a station. Each station should be given a number to facilitate discussion, and this should be indicated on the map so that there can be no doubt on the part of any pupil as to what region is referred to by a particular station number. A careful description of each station ought to be made by each pupil or by certain ones assigned to study special stations. In these, all biological and physical conditions that might in any way influence the fish life 
of a particular part of the stream should be described. This work will be much facilitated by making special maps of the region called stations and by taking photographs of them from different points of view.

The chief ways of getting facts about fish at a station are by collecting them for study and by observing them undisturbed in the stream. In regard to collecting: a certain amount of this will be necessary to acquaint pupils and teacher with the species of fish in the stream and to get facts concerning the exact nature of the food and to obtain data on some other problems. A small seine and one or more dip nets will be the most generally used pieces of apparatus for this work. Some of the fish collected should be brought alive to the laboratory and placed in aquaria. Valuable indoor exercises can be carried on with these, and by such sturdy pupils will be aided in identifying fish when seen in the stream. Representatives of each species of fish and of any other organisms taken with them should be placed at once in $10 \%$ formalin, but for humane reasons they may first be anesthesized by putting them in water containing a little chloroform. By placing fish in formalin while still living, they will die with their fins expanded, which makes them much better for study. Pupils should make careful notes on all parts of the stream where collections are made. The specimens taken at a particular station should be labeled and kept separate from those taken at other stations during the trip. These collections can be brought to the laboratory and given to pupils to sort into what seem to them to be different species. Such work I find of high value in training the discriminating powers of students. The specimens of each species of fish taken at a particular station on a certain date should be put in a wide mouth bottle or other preserving jar by themselves and covered with about three per cent formalin as a permanent preserving fluid. Each jar should have a gummed label, giving besides the station and date. the name of the species. If this name cannot be obtained at the school, the specimens can be sent to some specialist for determination. Most of our stream fish can be identified by Jordan's Manual of Vertebrates. Pupils can easily do this work after a little preliminary study of fish morphology so that they will understand the structures referred to and the terms used in the keys and descriptions given in this book. Identification exercises on fish with Jordon's Manual have been a regular part of my zoölogy courses given to second year normal school stu- 
dents during the last six years. The pupils have been almost invariably interested in the work, and it brings about a very noticeable improvement in their ability to make accurate and detailed observations. Not only will the specimens of fish from the stream furnish material for good laboratory work but they will form contributions to the school collection of local animal life.

The direct observation method of studying fish afield cannot be well carried on till the pupils have become acquainted with the appearances of at least the common fish as they are seen in the stream. This can be accomplished to a large extent by the laboratory and collecting methods already discussed. A good part of this work might be done prior to the spring term so that more time can then be used for field work. Since many fish, especially the larger ones, are shy, the class or individual observer should keep as far from the stream as convenient when making observations; and at all times be as inconspicuous as possible. Field glasses are almost as valuable in studying fish as they are in studying birds. A very successful method of seeing the normal actions of fish in a stream is to conceal oneself near a place where they are known to come forth, and wait for them to appear. By sitting almost motionless even in plain view, fish will after some time become accustomed to the sight of the person and give little heed to him. In riffles they can only be seen distinctly by means of a water glass. A simple water glass can be gotten by having a glass bottom put in an ordinary water bucket. By resting the bottom of this on a rough water surface and looking through it, objects can be clearly distinguished on the bottom where the stream is not too deep. Darters are easily found in this way, but of course the larger and shyer fish cannot be studied by this method.

There is a large number of problems concerning stream fish that can be studied by classes. How are the different species of fish in a stream related to each other? Some are closely associated and school together and take the same food and thus compete with each other in this respect. Some forms like pickerel, bass, and chubs feed upon other fish. There are several species that eat the eggs of other species and sometimes those of members of their own kind. Blunt-nosed minnows often flock in large numbers about nests of black-bass and sunfish to get the eggs if for any reason the fish guarding these nests are removed. It is well known that the peculiar little miller's thumb 
of our more northern streams eats brook trout eggs. The phenomenon of schooling is an interesting one to study. Are schools composed of one or more species? Do fish of a particular size tend to school together? Is a school composed of the same individuals at different times? Does it lose and gain members as it moves about? There are other questions concerning schooling that will suggest themselves as observation work proceeds. The ways fish effect each other can be studied by the direct observation and the collecting methods. For a good example of the kind of information concerning the associations of species that can be obtained by studying collections, see Professor Forbes' paper on the Local Distribution of Certain Illinois Fishes, published as a bulletin of the Illinois Laboratory of Natural History in April, 1907.

The study of the relation of fish to other organisms will bring one in contact with several fields of biology. There are a num ber of animals that feed upon fish, and the ecological relation of any one of them to fish life will make an interesting and important subject for study. There are many organisms that are parasitic on fish, including protozoans, worms, and small crustaceans of a number of kinds, and some fungi, a good example of which is the water mold, Saprolegnia. The larvae or glochidia of fresh water mussels, as is well known, are parasites on fish. Some of these can be removed from a mussel and placed in the aquarium; and their methods of attach ing themselves to fish can be noted. Whenever these are found on a specimen a record should be made of it. Fish also feed upon other organisms. To find out what these are, stomach examinations should be made, but some facts can be obtained by watching fish. Feeding habits are easily observed in many cases, and it is interesting to note the different ways our stream fish have of getting food. The suckers search the bottom with their long snouts; the top minnows glean the surface of the water; chubs and trout dash for insects that fall into the stream.

The distribution of fish in a stream is a perplexing subject. Daily anil hourly fluctuations in numbers at a particular station are often observed. At night some stream fish are in very different kinds of places from those in which they reside in the daytime. Fish may be abundant in a stream for several seasons, and then they seem to leave it and perhaps return to it again after a year or so, and we can see no changes in con- 
ditions for fish life during the time. These irregular movements are undoubtedly determined by laws about which we know little. What we want is data on this subject, and such data can be collected easily by secondary school classes. Careful notes should be made on all of the movements of fish, and efforts made to find causes for them. Pupils should attempt to discover the preferences that each species has in regard to habitat. What kind of environment does it select? The green sided darter, for example, will be found in shallow, swift water; the yellow catfish in deep holes usually with muddy bottoms. Classes might visit the stream at night to study distribution at that time. I have found an acetylene bicycle lamp excellent for iiluminating the stream bottom. Very few fish seem to be afraicl of this light. In regard to recording facts obtained about the distribution of fish, see an article in the American Naturalist for June, 1907, on A Graphic Method of Correlating Fish Environment and Distribution, by A. H. Wright.

A very attractive line of work is the study of colors of fish. Answers to such questions as these can be sought for: Is there any relation between the color of the fish and that of the bottom over which it is found? Are members of the same species of the same color wherever found? Can fish change their colors?

The study of the nesting habits of some of our stream fish should be an interesting line of work to follow with classes. Professor Reighard of the University of Michigan has obtained some facts concerning the breeding habits of our common creel: chub that might easily be verified by secondary school pupils The fish makes a nest typically in the form of a ridge of clean gravel extending lengthwise of the stream. All of these nests found by myself have been located in shallow water at the lower ends of pools into which the streams were broken and just above riffles. The male builds and attends the nest. Small stones are picked up by this fish from near the downstream end of the ridge and added to it. In this way the nest increases in length, growing in the downstream direction. The male is very shy when at work, and appears to see objects at some distance from the stream. When disturbed, he will dart to the deepest part of the pool or under an overhanging bank, and will not reappear for many minutes after the source of his alarm has vanished. Spawning takes place at the lower end of the nest, and the eggs become mixed with the stones. In a handful of gravel picked up from the newer part of the nest, several eggs can often be found. Pupils 
can bring these to the laboratory and hatch them, and rear the fish. I now have some chubs in an aquarium hatched from eggs collected in April, 1908. Professor Reighard has been successful in having classes study the habits of nesting chubs. Work with pupils can certainly be done by assigning individuals particular nests to study.

The blunt-nosed minnow which is so abundantly represented in our larger creeks and on the shoals of lakes has a nest that is very easily found. The eggs are placed on the flat under sides of stones on the bottom, close together in patches often composed of several hundreci eggs. A male fish of dark color and with a patch of horn like pearl organs upon his snout guards each patch of eggs. This fish is very bold, and its actions in protecting the eggs are easily observed at close range. Dozens of these nests can be found on a single trip. Pupils can count the eggs, and in this way get some notion as to the struggle for existence in the species.

The habits of nesting sunfish are well known. In streams in early summer males can be seen guarding their nests, which are depressions, more or less circular in form, in the bottom soil of shallow water in some quiet part of the stream. These nesting fish seem very fearless, and often suffer themselves to be touched or handled. One of these nests or a colony of them will provide many problems especially concerning the behavior of the fish toward other objects.

In studying fish nests, certain data should always be sought and recorded: the depth of water at which the eggs are placed, the temperature of the water about the eggs, the size and appearance of the eggs and the approximate number of them in the nest, and the actions of the attending fish toward the eggs and creatures that seek to injure them. Fish-nesting is a subject that requires much patience for its investigation, but it will prob. ably be found fascinating to most pupils, and any work that they do in this line can be stimulated by their knowing that there is a good chance for their adding new facts to our knowledge of fish, for little appears to be known about the breeding habits of the majority of our stream species. The paper on the Breeding Habits of the Rainbow Darter by Miss Reeves in the Biological Bulletin for December, 1907, and the one by Bertram G: Smith on Chrosomus erythogaster in the June, 1908, Biological Bulletin will give one ideas of what can be accomplished by a student of this stibiect. 